\title{
Peter Parker, White Supremacy, and Equity: The Need for Gifted Critical Race Theory
}

\section{Angela M. Novak, Ph.D.}

Dr. Scott Peters published "The Challenges of Achieving Equity Within Public School Gifted and Talented Programs" in Gifted Child Quarterly (2021).

https://journals.sagepub.com/doi/full/10.1177/00169862211002535

Along with this article, a team of special editors for GCQ issued a call for proposals for commentaries on this article:

https://journals.sagepub.com/pb-assets/cmscontent/GCQ/GCQ\%20Special $\% 20$ Issue $\% 20 \mathrm{Call} \% 2$ 0for $\% 20$ commentaries-1617034410.pdf

I submitted a 300-word proposal by April 16th (the due date), which was accepted, and I then had the opportunity to submit a full 1000-word response (by June 15).

About two months later (closer to the submission date) I finished writing my response. I knew I had a few words to cut, but I wanted to check on how many references I was allowed. I learned 10 references. And that my memory was poor- I had just written a TWO thousand word response, not ONE-thousand. :) This preprint contains the original 2085 response (unedited, with 851085 words to cut) and the copy submitted to GCQ.

I will be crafting this into a full article on GTCrit; comments and thoughts are welcome (novaka17@ecu.edu).

Edited 8/5: The updated and expanded version of this article is available as an Open Aceess chapter: https://wwigi-global.com/chapter/not-white-saviors-but-criticalseholars/290604 
Ooops I Wrote Too Much Again Response Non-Submission (2085 words) Peter Parker, White Supremacy, and Equity: A Call for Gifted Critical Race Theory

The editorial team at Gifted Child Quarterly invited commentary on the content and ideas presented by Peters (2021) "The Challenges of Achieving Equity Within Public School Gifted and Talented Programs", indicating that diverse perspectives contribute to the advancement of scholarship. I wholeheartedly agree that different lenses open our eyes to worldviews, and that contextualization is key in research. At the same time, common understanding around the use of shared vocabulary, a rejection of white-washed history, and an agreement to discontinue reliance on pseudoscience also contribute to the advancement of scholarship. Above all, a commitment to social justice as a society, to equitable reform guided by and through research, is foundational to the advancement of the field.

Dr. Peters' acknowledgement of his privilege provides contextual understanding of his positionality: "I write this article as one of the more privileged human beings on the planet... I try and remember that with privilege comes the responsibility to help those who are less privileged" (2021, p. 1-2). While Dr. Peters is sharing an example of his awareness of his advantage and professed commitment to equity, it also speaks to Ijeoma Oluo's comments in Mediocre, "Ours is a society where white culture is normalized and universalized, while cultures of color are demonized, exotified, or erased" (2021, p. 3). While the equity-titled article starts with a definition of disproportionality based on ethnicity, the content staggers into poverty as a co-morbidity of race. This is mirrored in the positionality statement which largely focuses on material advantages of Dr. Peters' SES rather than the white privilege of his skin. In a world built on systemic, culturalized white supremacy, privilege is provided based on skin color- not 
economics, not housing, not geography. It is implicit: nurtured and developed starting in childhood by master narratives, perpetuated by the educational and governmental systems, and preached from the pulpit.

Privilege is not a system of tokens where individuals get a sliding scale of coins to use on the racism merry-go-round of life based on degree of melanin. As a white woman, I don't hold more privilege tokens when I am pulled over by the police compared to the singular token held by my cousin, a Black man. White privilege exists for me in that when I was a child, I never had the talk with my parents- I never needed to have the talk- about what to do when stopped by the police to do my best to avoid being murdered. My cousin has no more or less privilege because of socio-economic status, the power and position of his parents (the former mayor and first lady of the community in which he resides), any summer camps attended, or his (or his spouse's) chosen career. White privilege, this palpable advantage situated in systemic racism, antiblackness, and white supremacy, exists for me in a way it does not for my cousin.

Those with this privilege maintain the status quo, because this is how the system was built, it "works according to design" (Oluo, 2021, p. 4). In the days, weeks, and months after George Floyd's murder at the knee of a white male, yet another clarion call was issued to the white community, and scores of specialists, interventionists, consultants, and researchers awakened and joined the equity train, vowing to help those without voices, finding new and better ways to fix children, fix curriculum, fix parents, fix tests, fix criteria, and so on. And yet, George Floyd was not voiceless; Floyd's voice was heard as he begged for his life. Gifted students of color are not voiceless, their voices are suffocated under the knee of systemic racism and white supremacy. 
Dr. Peters reminds us that, "with privilege comes the responsibility to help those who are less privileged" (2021, p. 2). Similarly, the Peter Parker Principle proverbializes: with great power comes great responsibility. The alternative is to use this whiteness, particularly the cross-section of whiteness and gender identity, not as a white savior, but as an intentional act of resistance and as a co-conspirator (Love, 2019). From this positionality, parents, educators, and researchers can advocate for the structural and systemic change that is sorely needed in gifted education. Thirty years after Peggy McIntosh's Invisible Knapsack article, my cousin can potentially walk into a store to find a bandaid the color of his skin, but this is not enough. The field needs reform, such as through the lens of critical race theory, not first aid.

Critical Race Theory (CRT) began in the domains of law and policy before being ushered into education by Billings and Tate (1995). Critical race theory scholarship is based on seeking answers to two essential understandings: "how a regime of white supremacy and its subordination of people of color have been created and maintained in America, ...examin[ing] the relationship between that social structure and professed ideals such as 'the rule of law' and 'equal protection'" (Crenshaw et al., 1995, p. xiii) and "second is a desire not merely to understand the vexed bond between law and racial power but to change it" (Crenshaw et al., 1995, p. xiii). Thus, critical race theory is not just a research lens for understanding systemic racism but it is a tool for social justice and change. For the remainder of my commentary, I offer the need for gifted education scholars, teachers, and administrators to take action as accomplices and co-conspirators, using critical race theory as a discourse for transformative change.

CRT operates within and across disciplines; within education there are five tenets that inform research, theory, and pedagogy (Solorzano, 1997; Solorozano \& Yosso, 2001; Yosso, 2017): 
The Intercentricity of Race and Racism with Other Forms of Subordination: Race and

racism are central to how our society operates. We cannot start the discussion with "does racism operate here?"; it does. We start with naming it and defining it. Other forms of subordination also exist; this intersectionality of race, gender, class, ability, phenotype, sexuality... all coexist and intertwine and create a shroud of oppression. In gifted education, the term $2 \mathrm{e}$, or twice exceptional, has been used to describe students that are both gifted and have an identified exceptionality, such as a learning disability or neurodiversity. 3e acknowledges the additional layer of oppression a gifted child has due to their skin color.

The Challenge to Dominant Ideology: Traditional educational structures make claims of objectivity, color blindness, and meritocracy. CRT challenges the educational system, calling out the deficit thinking ideology weaving through researchers, teachers, and administrators. CRT operates within the belief that the educational systems' claims of race neutrality and equal opportunity are masks for power and privilege in the self interest of the dominant group in society. Gifted education is not exempt from this deficit thinking model; Goings and Ford (2018) found that lamost half of the scholarly articles in a content analysis exhibited a deficit thinking ideology while writing about their sample.

The Commitment to Social Justice: Social justice in CRT is education as a transformative response to oppression, racial, gender, and class. This tenet may inform policy, curriculum, and pedagogy as much or moreso than research and theory, as it works towards the eradication of racism, sexism, and poverty and the empowerment of minoritized populations. Gifted education has operationalized aspects of social justice education within curricular models, however the use of resources outside the field more aligned to CRT, for example Cultivating Genius (Muhummad, 2020) with differentiation for the gifted, and an analysis of abolitionist teaching as professionals 
(Love, 2019), would push the field further along this social justice through education commitment.

Within this tenet lies the idea of interest convergence- Derrick Bell's theory, an originator of CRT in the law domain, that gains are made in the rights of Black citizens only when these gains will benefit white citizens as well. When the interests converge, or when White gains are part of the pot, the game is played to win. A subtle example of interest convergence is surface level diversity policies, in which a change is made to accomodate the diversity "movement": it is win/win- the gains are made for the minoritized group in the new policy, and the gains are made for the dominant group in good feelings about themselves, their public image, and their outward media perception. "Weak diversity policies fail to change the status quo today because they trade binding commitment for symbolism and good intentions (Shih, 2017, para 16). Adjusting cut off scores and using local norms for gifted programs is also interest convergence. There is a benefit to underrepresented populations, but there is also a benefit to white populations. Dr. Shih argues that interest convergence provides a lens for keener policy insight, "if the plan is ever broadly broadly perceived as disproportionately benefiting students of color, calls for cutting or eliminating its funding are highly likely" (2017, para 17).

The Centrality of Experiential Knowledge: CRT recognizes that the lived experiences of people from marginalized communities are essential to understanding race and racism. The dominant narrative does not tell the story. Consider the theory of acting white, the belief that gifted Black students underperform for fear of ostracization from their peers; since to achieve is to be white, or so the theory goes. What empirical support exists? Or, asked another way, have we queried gifted Black students for their perspectives? Toldson \& Owens (2010) determined 
through "analyses of relevant research and large national datasets, it can be concluded that the acting White theory for Black education is more fodder for cultural critics” (p. 95).

The Transdisciplinary Perspective: Contemporary and historical contexts, and cross- and inter-disciplinary perspectives are all taken into account in CRT, in order to analyze race and racism within the issue of study. The criticality of this in gifted education cannot be understated. Case in point: Peters (2021) paper, on which this commentary is based, asks why is there inequality in gifted education? One proffered answer: inequality in America, with the examples, under the negative life experiences heading, of poverty, leading to geographic place, then to neighborhoods, and to lead exposure. A transdisciplinary perspective considers the history of redlining and racialized housing practices, the economics of discriminatory hiring and inequitable wage practices, and the environmental racism evidenced by the lead poisoning crisis in the US.

The five themes or tenets of critical race theory are both theoretical and analytical. As CRT developed further from its initial law and policy roots into social sciences, history, and education, the foundational binary in which racism was articulated (Black/White) was called into question and expanded. New forms of discourse have emerged: Latina/o (LatCrit), Native American (TribalCrit), Asian American (AsianCrit), Women of Color (FemCrit), LGBTQIA+ (QueerCrit), White scholars exposing privilege and challenging racism (WhiteCrit), Dis/abilities studies (DisCrit). Each part of the CRT family tree, as it has expanded, has incorporated the racialized experiences of the different communities (Yosso, 2017). For example, while LatCrit has the tenet of intercentricity of race and racism with other forms of subordination like CRT, it takes into account the nuances of immigration status, accent, and surname that are parts of their identity, their intersectionality in ways that the traditional racism binary does not. 
Dis/ability critical race studies (DisCrit) recognizes that "racism and ableism are normalizing processes that are interconnected and collusive.... [They] often work in ways that are unspoken, yet racism validates and reinforces ableism, and ableism validates and reinforces racism (Annamma et al., 2013, p. 7), thus it provides a framework that postulates how race, racism, ableism, and dis/ability work within and among the systems and structures of education, disproportionately impacting students of color. It is in this vein that I proffer GTCrit, a theoretical and analytical lens, both a way of understanding and an impetus for social change. GTCrit is a framework that theorizes about the ways in which race, racism, ability, potentiality, and deficit ideology are built into the daily interactions and discourses, informal and formal policies and procedures, and the systems and structures of education, which disportionality impact students of color qualitatively differently than white students.

Dr. Peters wrote an article on the challenges of achieving equity in public school gifted programs, and these challenges are great indeed. I appreciate the opportunity to contribute to this commentary with GTCrit. As gifted education joins the critical race theory discourse, i.e. analyzing present day circumstances through a historical and socio-cultural lens that takes into account white washed history and the ever-present culture of white supremacy, the field can work together towards real systemic and structural change.

\section{References}

Crenshaw, K. W., Gotanda, N., Peller, G., Thomas, K. (1995). Introduction. In Crenshaw, K., Gotanda, N., Peller, G., Thomas, K. (Eds.), Critical race theory: The key writings that formed the movement (pp. xiii-xxxii). New Press. 
Goings, R. B. \& Ford, D.Y. (2018). Investigating the intersection of poverty and race in gifted education journals: A 15 year analysis. Gifted Child Quarterly, 61(1), 25-36. DOI: $10.1177 / 0016986217737618$

Ladson-Billings, G. \& Tate, W. (1995). Towards a critical race theory of education. Teachers College Record, 97(1), 47-68.

Love, B. L. (2019). We want to do more than survive: Abolitionist teaching and the pursuit of educational freedom. Beacon.

Oluo, I. (2020). Mediocre: The dangerous legacy of white male America. Seal Press. Peters, S. J. (2021). The challenges of achieving equity within public school gifted and talented programs. Gifted Child Quarterly. 1-13.

https://doi.org/10.1177/00169862211002535

Shih, D. (2017, April 19). A theory to better understand diversity, and who really benefits. NPR. Code Sw!tch. Race. In Your Face.

https://www.npr.org/sections/codeswitch/2017/04/19/523563345/a-theory-to-better-under stand-diversity-and-who-really-benefits

Solorzano, D.G. (1997). Images and words that would: Critical race theory, racial stereotyping, and teacher education. Teacher Education Quarterly, 24, 5-19.

Solorzano, D.G., \& Yosso, T.J. (2001). Critical race and LatCrit theory and method: Counter-storytelling. Chicana and Chicano graduate school experiences. Qualitative Studies in Education, 14(4) 471-495.

Toldson, I.A., \& Owens, D. (2010). “Acting Black”: What Black kids think about being smart and other school-related experiences. The Journal of Negro Education, 79(2), 91-96. 
Yosso, T.J. (2017). Whose culture has capital? In A.D. Dixson, C.K. Rousseau Anderson \& Jamel K. Donnor's (Eds.). Critical race theory in education: All God's children got a song (2nd Ed.). (pp. 113-136). Routledge. 


\section{GCQ Response Submission (995 words)}

\section{Submitted 6/15/2021}

\section{Peter Parker Principle: From White Privilege to Gifted Critical Discourse}

With the understanding that diverse perspectives contribute to scholarship, different lenses open our eyes to worldviews, and that contextualization is key in research, I offer this brief commentary on Peters (2021) article on challenges to achieving equity within public gifted programs. While the article starts with a definition of disproportionality based on ethnicity, the content staggers into poverty as a co-morbidity of race. This is mirrored in the positionality statement which largely focuses on material advantages of Peters' economic status rather than his white privilege. "I write this article as one of the more privileged human beings on the planet," Peters acknowledged (2021, p. 1-2). As a white woman, I don't hold more privilege when I am pulled over by the police compared to my cousin, a Black man. My cousin has no more or less privilege because of socio-economic status, the power and position of his parents, summer camps he attended, or his (or his spouse's) chosen career. White privilege exists for me in a way it does not for my cousin. It is nurtured starting in childhood by master narratives, perpetuated by the government, and preached from the pulpit.

Those with privilege maintain the status quo, because this is how the system was built, it "works according to design" (Oluo, 2021, p. 4). Peters remarked, "I try and remember that with privilege comes the responsibility to help those who are less privileged" (2021, p. 2). As the Peter Parker Principle proverbializes: with great power comes great responsibility. The alternative is to use this whiteness, particularly the cross-section of whiteness and gender identity, not as a white savior, but as an intentional act of resistance and co-conspirator (Love, 
2019). From this positionality, stakeholders can advocate for structural change that is sorely needed in gifted education, such as through critical race theory.

Critical Race Theory (CRT) began in law and policy before being ushered into education by Billings and Tate (1995). CRT is a research lens for understanding white supremacy, racism and the systems of power and oppression upheld through the rule of law and equal protection under the law. It is also a tool for social justice and change. For the remainder of my commentary, I suggest that gifted education use CRT as a discourse for transformative change, following the five tenets of CRT that inform research, theory, and pedagogy (Solorzano, 1997; Yosso, 2017):

The Intercentricity of Race and Racism with Other Forms of Subordination: Race and racism are central to how our society operates. Other forms of subordination include the intersectionality of race, gender, class, ability, phenotype, and sexuality. In gifted education, the term 2e, or twice exceptional, describes students that are gifted and have an identified learning disability or neurodiversity. $3 \mathrm{e}$ acknowledges the additional layer of oppression a gifted child experiences due to race.

The Challenge to Dominant Ideology: CRT challenges the educational system, calling out the deficit thinking ideology exhibited by researchers, teachers, and administrators. Goings and Ford (2018) found that almost half of the scholarly articles in a content analysis of gifted education articles exhibited a deficit thinking ideology.

The Commitment to Social Justice: Social justice in CRT is education as a transformative response to oppression. Within this tenet lies interest convergence, that gains are made in the rights of Black citizens only when these gains will benefit white citizens as well. When the interests converge, or when white gains are part of the pot, the game is played to win. Adjusting 
cut off scores and using local norms for gifted programs is interest convergence. There is a benefit to minoritized and also white populations.

The Centrality of Experiential Knowledge: CRT recognizes that the lived experiences of people from marginalized communities are essential to understanding race and racism. Acting white is the theory that (gifted) Black students underperform for fear of ostracization from their peers. Have we queried gifted Black students for their perspectives? Toldson \& Owens (2010) determined through "analyses of relevant research and large national datasets, it can be concluded that the acting White theory for Black education is more fodder for cultural critics" (p. 95).

The Transdisciplinary Perspective: Contemporary and historical contexts, and cross- and inter-disciplinary perspectives are all taken into account in CRT, in order to analyze race and racism within the issue of study. Case in point: Peters (2021) asks why is there inequality in gifted education? One proffered answer: inequality in America, with the examples of negative life experiences of poverty, leading to geographic place, then neighborhoods, and lead exposure. A transdisciplinary perspective considers the history of redlining and racialized housing, the economics of discriminatory hiring and inequitable wage practices, and the environmental racism evidenced by the lead poisoning crisis.

As CRT developed further from its initial law roots into social sciences, history, and education, new forms of discourse emerged such as Latina/o (LatCrit), Native American (TribalCrit), and Dis/abilities studies (DisCrit). As each part of the CRT family tree has grown, it has incorporated the racialized experiences of its representative communities (Yosso, 2017). For example, diis/ability critical race studies (DisCrit) recognizes that "racism and ableism are normalizing processes that are interconnected and collusive" (Annamma et al., 2013, p. 7), thus 
it provides a framework that postulates how race, racism, ableism, and dis/ability work within and among the systems and structures of education, disproportionately impacting students of color.

Similarly, I suggest GTCrit, a theoretical and analytical lens, both a way of understanding and an impetus for social change. GTCrit is a framework that theorizes about the ways in which race, racism, ability, potentiality, and deficit ideology are built into daily interactions and discourses, informal and formal policies and procedures, and the systems and structures of education, which disportionately impact students of color qualitatively differently than white students.

I appreciate the opportunity to participate in this commentary process; a commitment to social justice as a society, to equitable reform guided by and through research, is foundational to the advancement of the field. 


\section{References}

Crenshaw, K. W., Gotanda, N., Peller, G., Thomas, K. (1995). Introduction. In Crenshaw, K., Gotanda, N., Peller, G., Thomas, K. (Eds.), Critical race theory: The key writings that formed the movement (pp. xiii-xxxii). New Press.

Goings, R. B. \& Ford, D.Y. (2018). Investigating the intersection of poverty and race in gifted education journals: A 15 year analysis. Gifted Child Quarterly, 61(1), 25-36. DOI: $10.1177 / 0016986217737618$

Ladson-Billings, G. \& Tate, W. (1995). Towards a critical race theory of education. Teachers College Record, 97(1), 47-68.

Love, B. L. (2019). We want to do more than survive: Abolitionist teaching and the pursuit of educational freedom. Beacon.

Oluo, I. (2020). Mediocre: The dangerous legacy of white male America. Seal Press. Peters, S. J. (2021). The challenges of achieving equity within public school gifted and talented programs. Gifted Child Quarterly. 1-13.

https://doi.org/10.1177/00169862211002535

Solorzano, D.G. (1997). Images and words that would: Critical race theory, racial stereotyping, and teacher education. Teacher Education Quarterly, 24, 5-19.

Toldson, I.A., \& Owens, D. (2010). “Acting Black": What Black kids think about being smart and other school-related experiences. The Journal of Negro Education, 79(2), 91-96.

Yosso, T.J. (2017). Whose culture has capital? In A.D. Dixson, C.K. Rousseau Anderson \& Jamel K. Donnor's (Eds.). Critical race theory in education: All God's children got a song (2nd Ed.). (pp. 113-136). Routledge. 
